\section{TUNABLE CLATHRATES}

T. le Roex M.R. Caira L.R. Nassimbeni

University of Cape Town Dept. of Chemistry, Rondebosch, CAPE TOWN 7701 SOUTH AFRICA

The host compound trans-9,10-dihydroxy-9,10-bis(p-tert-butylphenyl)-9,10dihydroanthracene forms inclusion compounds with N,N-dimethylformamide (DMF), dimethylsulphoxide (DMSO) and acetone of the type $\mathrm{H}_{n} \mathrm{~A}_{4-\mathrm{n}} \mathrm{B},(\mathrm{A}, \mathrm{B}=$ guests), with $\mathrm{n}$ varying integrally from 0 to 4 . The structures of these compounds have been elucidated. The DMF-DMSO compounds are all triclinic and crystallise in the space group $P-1$. They are isostructural with respect to the host molecules and within the host framework, the guests fill certain sites interchangeably. Where $\mathrm{n}$ is odd, one particular site is shared by two different guests, making refinement difficult. There is extensive hydrogen bonding between the host and guests in these structures. This host readily absorbs acetone from the vapour phase and under isothermal conditions the velocity of guest uptake is proportional to the vapour pressure of the guest. We have noted that there is a threshold pressure, Po, below which the reaction does not take place. This phenomenon gives rise to anti-Arrhenius kinetic behaviour in that for a given vapour pressure, the enclathration reaction is slower at higher temperatures. The desorption process follows first order kinetics with an activation energy of $48.4 \mathrm{~kJ} / \mathrm{mol}$.

\section{Keywords: CLATHRATES, KINETICS, THERMAL STABILITY}

Acta Cryst. (2002). A58 (Supplement), C311

\section{DETECTION OF ALKALI METAL IONS BY FLUORESCENT SIGNALLING CROWN ETHERS}

J. F. Malone A. Alves-Areias A. P. deSilva T.S. Moody Queens University of Belfast School of Chemistry David Keir Building Stranmillis Road, Belfast NORTHERN IRELAND BT9 5EH UK

The development of sensors for cations important in life processes, e.g. $\mathrm{H}^{+}$, $\mathrm{Na}^{+}, \mathrm{K}^{+}$or $\mathrm{Ca}^{+}$, finds wide application in the medical and biotechnological fields. Crown ethers have had extensive use as constituent parts of molecular luminescent sensors which rely on photo-induced electron transfer (PET) for sensing purposes, i.e. by the on-off switching of fluorescence. For example anthracene fluorescence is quenched by PET from a nitrogen lone pair on an attached metal-free aza-crown ether, but is restored in a metal-bound complex, with varying fluorescence enhancements depending on the crown and on the metal. Quantum yield can be explained in terms of the charge density, the cation solvation and the geometry of contact of the metal with the PET active site. In this work solution phase studies of fluorescence enhancement for a family of structurally related sensors complexing Group I metal cations have been complemented with solid phase crystal data. Structural details from X-ray crystal structure determinations of metal-free receptor molecules containing monoaza-15-crown-5 or monoaza-18-crown-6 moieties and of single and double crown ethers complexed to $\mathrm{Na}^{+}, \mathrm{K}^{+}, \mathrm{Rb}^{+}$or $\mathrm{Cs}^{+}$have been examined and the geometrical details of structure have been correlated with the fluorescence enhancement quantum yields achieved by each.

\section{Keywords: FLUORESCENCE PHOTO-INDUCED ELECTRON TRANSFER ALKALI METAL IONS}

\section{Acta Cryst. (2002). A58 (Supplement), C311 \\ CALIX[4]ARENE LOWER RIM IONIC INTERACTION AND THE FORMATION OF INTRA-MOLECULAR COMPLEXES}

$\underline{\text { O. E. Piro }}^{1}$ E. E. Castellano ${ }^{2}$ A. F. Danil de Namor $^{3}$

${ }^{1}$ Facultad De Ciencias Exactas, Universidad Nacional De La Plata Departamento De Fisica 49th and 115th Streets C.C. 67 LA PLATA BUENOS AIRES 1900 ARGENTINA ${ }^{2}$ Instituto de Fisica de Sao Carlos, Universidade de Sao Paulo, C.P. 369, 13560 Sao Carlos (SP), Brazil ${ }^{3}$ Laboratory of Thermochemistry, Department of Chemistry, University of Surrey, Guildford, Surrey, UK GU2 5XH

Several macrolactames containing in their structure biphenyl and pyridine moietis have been synthesized. Ability in complexation for these compounds have been evaluated and results have been explained because of the formation of intramolecular hydrogen bonds. Configurational studies have been developed in same cases.

The studied compounds (Figure 1) contain in their structure a pyridine ring to provide rigidity to the structure. Additionally the presence of the amide and ester group make the complexating cavity more rigid and allowes to study the stereochemistry of the complexation process.
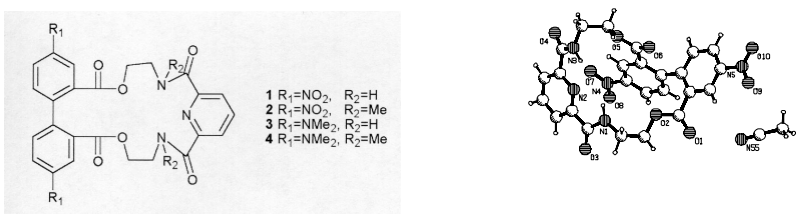

Figure 1.- Scheme of studied compounds. Figure 2.- View of X-ray solved structure.

Crystal structure of $\mathbf{1}$ (Figure 2) has been determined from direct methods which on refinement yielded a final value of $\mathrm{R}$ index as 0.0493 . The compound crystallizes in the monoclinic space group $P 2_{1} / \mathrm{n}$ with unit cell parameters $a=$ $10.6422(5) \AA, b=16.6551(5) \AA, c=15.2908(5) \AA, \beta=101.06(5)^{\circ}$.

The macrocycle is stiffened by intramolecular hydrogen bonds $\left(\mathrm{N}-\mathrm{H}_{\text {amide }} \cdots\right.$ $\mathrm{N}_{\mathrm{py}}$ ). The presence of such hydrogen bonds is known to stabilise flat syn-syn conformations for compounds containing 2,6-dicarbamoyl pyridine moieties.
Allosteric effects are common in large organic systems: conformational modifications in a molecular region promote changes in other molecular parts. These synergetic effects are present in calix[4]arene compounds, where four phenyl rings enclose a hydrophobic pocket capable to interact and host small neutral organic molecules. By replacing the phenolic $\mathrm{H}$-atoms by appropriate residues, a hydrophilic cavity can be created in the lower molecular rim where ionic and/or H-bonding interactions could occur. As a consequence, these calixarene derivatives act as bi-functional receptors of a small solvent molecule in the calyx and charged species in or around the hydrophilic cavity. The molecular structure of \{tetrakis[4-(ethyl)morpholine]oxyl\} p-tertbutylcalix[4]arene (1) and of the acetonitrile complex of the protonated calixarene trifluoromethanesulfonate salt $(\mathrm{MeCN})_{1} \mathrm{H}\left(\mathrm{CF}_{3} \mathrm{SO}_{3}\right)_{4}$ (2) were determined by X-ray diffraction methods from 13876 (1) and 10478 (2) reflections with $\mathrm{I}>2 \sigma$ (I) and refined to R1-values of 0.084 (1) and 0.081 (2). The calyx of both independent molecules of 1 presents a squashed cone conformation where a pair of opposite phenyl rings are close to mutual perpendicularity while the other pair are nearly parallel to each other, a conformation exhibited by a whole variety of p-tert-butylcalix(4)arene derivatives which does not favor accommodation of a solvent molecule. In 2 , ionic interactions mediated by $\mathrm{H}$-bonding of the $-\mathrm{O}\left(\mathrm{CH}_{2}\right)_{2} \mathrm{NH}^{+}\left(\mathrm{CH}_{2}\right)_{4} \mathrm{O}$ pendant arms with $\mathrm{CF}_{3} \mathrm{SO}_{3}{ }^{-}$ions, promote the symmetric opening of the calyx and its subsequent filling with an acetonitrile solvent molecule to form an intramolecular complex (positive allostery).

\section{Keywords: CALIX[4]ARENE, MOLECULAR COMPLEX, ALLOSTERY}

